\title{
Palabras, creencias y ritos relacionados con el muqui, el duende de las minas
}

\author{
Words, beliefs, and related rites to the muqui, the goblin of the mines
}

Rosa Carrasco Ligarda ${ }^{1}$

\begin{abstract}
RESUMEN
Se presenta una selección de términos relacionados con el muqui (el duende de las minas) que se emplean en zonas mineras donde existe galerías y túneles mediante los cuales se llega a las vetas. Además, los apelativos que se aplican al duende, la caracterización física y psicológica que se le ha atribuido. También se analizan las palabras relacionadas con los ritos y las ofrendas. Finalmente, los términos empleados para referirse a las personas responsables de realizar las ceremonias en rituales o de ejecutar ciertas actividades conexas.
\end{abstract}

\section{Palabras clave}

Muqui, creencia, ritos, mina, ofrendas.

\begin{abstract}
It presents a selection of terms related to the muqui (the goblin of the mines) that are employed in the mining regions where drifts and tunnels are to get to the veins. Furthermore, the physical and psychological description, and nicknames that are attributed to the goblin. Besides, words related with rites and offerings are analyzed. Finally, terms employed to refer to the people responsible of performing ceremonies in rituals or implementing some related activities.
\end{abstract}

\section{Keywords}

Muqui, belief, rites, mine, offerings.

El muqui, duende de las minas, pertenece a la tradición oral y habita en el uku pacha o mundo de adentro, de la oscuridad y subterráneo, desconocido y vedado al ser humano. De acuerdo a Mircea Eliade, ingresar en el mundo del subsuelo y la mina es "introducirse en una zona reputada como sagrada e inviolable, se perturba la vida subterránea y los espíritus que la rigen; se entra en contacto con una sacralidad que no pertenece al universo religioso familiar, sacralidad más profunda y también más peligrosa" (Eliade 1959: 57). Concepciones semejantes existen en todo el mundo, se ve el subsuelo como una realidad paralela regida por otros parámetros. En el Perú, de acuerdo con las creencias, está habitado por presencias propias, de manera semejante a "Todas las mitologías de las minas y las montañas, donde todos los innumerables genios, hadas, fantasmas y espíritus son las múltiples epifanías de la presencia sagrada que se afronta cuando se penetra en los niveles geológicos de la Vida" (Eliade 1959: 58).

\section{Los nombres del muqui}

De entre los duendes del Perú (ichic ollco, auquillo, equeco, chulla chaqui, etc.), la creencia en el muqui es la más vigorosa. Es una presencia central en el mundo subterráneo de los socavones y galerías de las minas en el Perú y Bolivia, realidad diferente de las minas a tajo abierto ${ }^{1}$, donde la entidad muqui se difumina bajo el nombre genérico "espíritus", según informe de Arequipa.

1 Doctora en Filología por la Universidad Complutense de Madrid. Tiene tres maestrías. Directora del Centro de Investigación de la Universidad Femenina del Sagrado Corazón. Docente ordinaria de la UNIFÉ.

2 Una mina a tajo abierto está en la superficie de la tierra y expone el mineral a la vista. 
El nombre muqui se conmuta con otros apelativos en relación con el lugar, la valoración del año y la afectividad. Según el lugar, se le llama muqui en Cerro de Pasco, Junín, Ayacucho, Cuzco, Apurímac, Cajamarca (Yanacocha), Oyón y Arequipa (aunque en esta última, coexiste con el apelativo chinchilico, al igual que en Canta); mientras en Puno solo se usa el nombre chinchilico. En cambio, en Bolivia (Potosí) es anchanchu ${ }^{3}$, tío ${ }^{4}$ $y$ otorongo; $y$ en San Antonio de Putina, en Ananea (Puno), se le denomina con cariño juanikillo o awichita. En Cajamarca se llama jusshi. Otros apelativos son supay muqui ('diablo muqui'), muqui supay, tayta o tayta muqui ('papá muqui').

\section{El porqué de los rituales}

Según las creencias, las fuerzas sobrenaturales del mundo mágico determinan lo favorable o desfavorable que pueda resultar un año, en términos de riqueza mineral extraída de la mina con facilidad y sin contratiempos. Esa relación con la extracción del mineral motiva rituales de los mineros para asegurar un trabajo exitoso y/o contrarrestar las dificultades. Así, en Huancavelica, cuando la valoración del año indica que este ha sido apacible, sin huelgas ni accidentes, al duende de la mina se le llama muqui; anchancho —-según Salazar-Soler-, si la valoración es negativa; si fue muy malo lo llaman supay ${ }^{5}$; y si ha sido pésimo, arrierito.

Posiblemente en los años nefastos, al muqui se lo llama supay o arrierito por su poder de transportar el mineral de una zona a otra a lomo de llama o de hacerlo aparecer o desaparecer en la mina, puesto que aunque no produce el mineral, es el guardián o dueño y puede cambiarlo de lugar. Esto explica las invocaciones de los mineros solicitándole que transporte el mineral y que enriquezca la mina. Generalmente es al muqui a quien se entregan las ofrendas. Para los trabajadores, el muqui es una presencia concreta en la mina, a veces visible; los conoce, vigila, les hace bromas y en algunas oportunidades establece una relación directa con ellos.

Como los seres sobrenaturales relacionados con la tierra son varios - la pachamama (madre tierra), el auquillo o jirca (duende anciano espíritu de los cerros), los apus o wamanis (espíritu de la montaña o cerros)_, puede privilegiarse la importancia de cualquiera de ellos y se le presentan ofrendas. Por ejemplo en Oyón, provincia limeña, la deidad con mayor relevancia es la Pachamama; por esa razón, si hay accidentes pequeños o fatales en la mina: "... los mineros ofrecen sacrificios de animales como en el huilancho ${ }^{6}$, donde sacrifican una llama hermosa de color blanco y pura, como la representa su color, para aplacar la ira o la cólera de la Pachamama y continuar así trabajando con cierta seguridad" (Rodríguez 2004: 24).

\section{Conceptos relacionados con la palabra muqui}

Según veremos, en la palabra muqui 'duende de las minas' convergen diferentes significados de raíces homófonas: aimara muk'i 'húmedo'; quechua de Áncash muki 'tierra roja'; quechua del Cuzco muki 'asfixia', 'sofocación'.

\footnotetext{
Nombre aimara de los seres que habitan en cuevas y lugares húmedos.

4 Bernabé Cobo dice que los nativos alcanzaron a comprender que había un dios creador universal de todas las cosas. Explica que en su lengua no tienen el sonido de la d, por lo cual en lugar de pronunciar "Dios" dicen "Tío". Continúa Cobo: "para instruirlos en la doctrina cristiana, se pone nuestro nombre Dios y dél usamos siempre que hablamos con ellos, a causa de no haber en su lengua palabra que con propiedad le corresponda; y los mismos indios cristianos lo tienen y usan ya por tan propio como nosotros, dado que en la pronunciación difieren algo los que no son ladinos españolados; porque como no tuvieron en su lengua $\mathrm{D}$, sino que en lugar della usaban desta letra, $\mathrm{T}$, así, en lugar de decir Dios, suelen pronunciar Tios" (Cobo 1964 Ś1533Ș, t. II, libro XIII: 155).

5 En 1560 fray Domingo de Santo Tomás en su Lexicón tradujo la palabra çupay como "angel bueno o malo". Los doctrineros acuñaron la acepción maléfica; y así en el Vocabulario de Gonçález Holguín, en la segunda parte, leemos: "Diablo. Çupay Ś...Ș" (Gonçález H. 1952 Ś1608Ș). Actualmente, supay se define como diablo. La relación se orienta a la codicia y a la inescrupulosidad, evidente en los ritos con ofrendas humanas, en la explotación con caracteres infrahumanos y hoy en los asesinatos de las personas que ya han logrado cierta cantidad de oro y deciden retirarse.

6 De wilancha, palabra aimara derivada del verbo wilanchaña 'ensangrentar'. En la fiesta del Inti Raimi, también se llama wilancha a la ceremonia del sacrificio de una llama para determinar presagios y venturas.
} 
Como son varios los conceptos relacionados con la palabra muqui, vamos a iniciar presentando la palabra muqui en su significado de 'húmedo'.

Ludovico Bertonio, en su Vocabulario de la lengua aymara (1984 [1612]), presenta el adjetivo "muki, Mori. Húmedo, Mojado" (donde $\mathrm{k}$ representa la oclusiva velar glotalizada sorda $/ \mathrm{k}^{\prime} /$ ). Esa acepción coincide con la consignada por Jorge Lira y Mario Mejía Huamán (2008 [1942]) "múk'i. adj. Húmedo." y con el sustantivo "Múk'i-múhu: semilla húmeda". A su vez, armoniza con uno de los referentes que el imaginario popular ha acuñado sobre uno de los hábitat del ya aludido anchanchu, según registra Hans Van Der Berg en su Diccionario religioso aymara: "Mora en los fondos de los ríos, en las cuevas y en las grietas de las montañas, en las quebradas, bajo tierra en lugares desolados y en casas deshabitadas".

Ese vínculo del muqui con la humedad también se encuentra registrado en el Cuzco por Rosalind Gow y Bernabé Condori: "Los diablos criados por la Tierra son los Anchanchus, los Sirinos, los Cohua y los Soq'a Machulas. Son los hijos de la Tierra, saben andar detrás de ella. [...] Viven más en el agua, en los manantiales y en las rocas. No pueden vivir en la tierra" (Gow y Condori 1976: 70). Aquí se puede establecer una conexión con el ichic ollco, el duende que habita en los manantiales y molinos, y tiene algunas semejanzas con el muqui, por ejemplo, su afición por las mujeres, su libido desarrollada, y ser causante de la muerte de personas.
Otro concepto relacionado con muqui se encuentra en la palabra compuesta caruamuqui, cuyo significado es 'polvo de color amarillo'. En Extirpación de idolatrías (1621), que se basa en indagaciones en Huarochirí, de Pablo Joseph Arriaga, hay dos registros de la palabra muqui; la primera referida a ofrendas a las huacas: "paria ${ }^{7}$ son polvos de color colorado como de bermellón que traen de las minas de Huancavelica, que es metal que se saca del azogue, aunque más parece acarçón. Binços ${ }^{8}$ son polvos de color azul muy fino, Llacsa ${ }^{9}$ es verde en polvos, o en piedra como el cardenillo. Carvamuqui ${ }^{10}$ es polvo de color amarillo" (Arriaga 1920 [1621]: 47)

La segunda referencia de Arriaga alude a la información que debe dar el hechicero sobre los elementos que emplea en las ofrendas y se le interroga sobre el caruamuqui (pero Arriaga escribe como dos palabras separadas: "Carva" y "Muqui"). Según las instrucciones, el extirpador de idolatrías debía conminar para que el interrogado declarase "el oficio que tiene de Hechizero (si lo es) y la Huaca, y Malquis que han adorado, y las Conopas, $y$ dioses Penates que tienen en su casa. Y las ofrendas de mullu, Paria, Llacsa, Carva ${ }^{11}$, Muqui, Ato, Huahua, Sebo, Coca, Sancu, y las demás" (Arriaga 1920 [1621]: 143).

Otra referencia sobre la palabra caruamuqui como polvo empleado en hechicería se encuentra en un expediente de 1617 levantado por el visitador de idolatrías bachiller Francisco

Es el cinabrio. "Cinabrio, nombre en quechua paria, si bien se empleaban otras denominaciones, se usaba como colorante y para pintarse el rostro y cosmético (Huancavelica: Chonta, Provincia Dos de Mayo en Huánuco, Santa Cruz en). (Samamé Boggio 1979: 27). Cinabrio. Mineral compuesto de azufre, mercurio, color rojo oscuro; de él se extrae el azogue o mercurio. (Gentile 1999: 428).

8 "Lazurita, Lapislázuli, sirvió como materia prima para fabricar el color ultramarino, así como piedras de adorno, de aspecto similar: dumortierita, y probablemente en Cerro Verde, Ayacucho y Canta)" (Samamé Boggio 1979: 28).

9 El diccionario de Gonçález Holguín consigna "Llacsa. El metal fundido, o bronze chacrusca antacta, llacsani, o, chacruni. Mezclarlo" (Holguín, 1952 Ś1608Ș). Samamé Boggio lo define como: "Calcita; Cardenillo (Carbonato de cobre), nombre en quechua l'ah'sa, se llama también ancas llimpi; Casiterita (especies similares: wolframita, Zircón, Granate, Vesubiana)" (Samamé Boggio 1979: 27). "Atacamita (Nazca, Ica, Tarapacá, Atacama, Cerro Verde del Tambo del Cortaderal entre Islay y Atequipa, Acarí, Camaná, Tingue, Cerro Verde, Cerro Trinidad, Huantajaya, Ilo, Pacocha, Chala, Camaná, Pampa Colorada), nombre indígena lájsa (según Tschudi esta palabra no pertenece al quechua)" (Samamé Boggio 1979: 27).

10 La cursiva es nuestra.

11 "Pirita, nombre quechua relacionado con quillo o carhua, color amarillo; quillo, amarillez; caruayani-gui, quilloyanigui, amarillarse, y muchos otros derivados" (Samamé Boggio, 1979: 29). 
de Estrada que menciona Luis E. Valcárcel en la Región Huanca en el pueblo de San Miguel de Ullucmayo. Señala que en el registro de la casa del mago Llaxsahuarco "se encontraron dentro de una despensa muchos papeles, talega y atados de polvos azules llamados Llacsa, de polvos amarillos o carhuamuque, de polvos anaranjados o epiguanan de oropel o carhua y cuentecillas coloradas y azules, estas últimas para que la araña las comiese" (Valcárcel 1984: 152). Lo que se puede deducir es que la palabra caruamuqui está relacionada con un polvo amarillo empleado en hechicería en el incanato. También actualmente esos polvos minerales se emplean en las ofrendas al muqui, pero ¿de qué mineral se trata?

Hemos visto que las voces carva, muqui y caruamuqui son quechuas. En el contexto actual se puede señalar que en las ofrendas incaicas, "carua" es considerada una piedra preciosa ofrecida a las huacas. Ese valor difiere de una apreciación actual de ese mineral, ya que se trata de la pirita (también llamada "quillo" < qillu 'amarillo'), pero se la confunde con el oro por su color amarillo.

El significado de carua como 'amarillo' fue general en el quechua junto con qillu. Una referencia que lo demuestra es la entrada carua /qarwa/ en el Lexicón de Domingo de Santo Tomás (1560), en la que la define como "cosa mustia, o amarilla" y "caruayani, gui marchitarse alguna cosa". La base léxica qarwa ('amarillo') también figura en el vocabulario de Gonçalez Holguín (Gonçalez Holguín 1952 [1608]), referida al color de las plantas secas y amarillentas, y persona enferma y amarillenta ${ }^{12}$. Durante la Colonia era un término ampliamente conocido en esa acepción de color, como lo revela el nombre del pueblo San Francisco de Caruacucho (en Ayacucho) llamado así por el sentido de qarwa como 'tierra amarilla' y kuchu 'rincón'. Este registro y otros demuestran que era aplicada en palabras compuestas como "carua calia" apelativo recogido en Cajatambo en un proceso de extirpación de idolatrías el cual se lo describe como un ídolo "llamaba el ydolo Carua calia el cual es como un huego de paloma y parece ser de metal de plata y no tiene figura alguna sino como un piñoncito pequeño" (Duviols 1986: 22). Se puede señalar que caruamuqui es una palabra compuesta relacionada con ritos esotéricos en el incanato y carua está registrada en los lexicones del siglo XVII, no así muqui. ¿Se trata de un término vetado por referirse a una deidad particular?

No se ha perdido la palabra caruamuqui, pues aún se la emplea en el rito para curar el muquihuayra ("viento del muqui" viento nocivo que produce gangrena). Los mineros consideran que esa dolencia se produce como un castigo del muqui:

Esta enfermedad es curada por el Muqui a través de su pongo. Este hace primero sus consultas a la divinidad de la mina. [...] Durante esta consulta, ofrece al Muqui hojas de coca, cigarros y una mezcla a base de alcohol y de polvos minerales -huinzo (polvo azul), qarwamuqui (polvo amarillo) y bermellón (polvo rojo) — que ha dejado en su mate. El pongo arroja este mate invocando al Muqui y preguntándole si la persona en cuestión ha sido atacada por él; si el mate cae sobre su base; la respuesta del Muqui es positiva. (SalazarSoler 2006: 164)

Se ha considerado la relación del color amarillo con el muqui. Carmen Salazar-Soler dice: "Si carua designa el color amarillo, podríamos pensar que muqui está asociado al polvo o al mineral que le corresponde, lo que equivaldría al oropimente (Santo Tomás 1951[1563]). No olvidemos que los mineros de Huancavelica dicen que el cuerpo del muqui está constituido de mineral" (Salazar-Soler 1997), al igual que en Oyón. Sin embargo, respecto a la identificación cromática del muqui solo en algunas versiones su ropa es de oro; y su

12 "Karhua huaqquello. Las miesses, yeruas, hojas agostadas secas y amarillas, o blanquecinas. / Karhuayan qqelloyan çara. Trigo estar seco el mayz o trigo sazonado para coger, o agostado. / Kar huayani, o qquelloyani. Andar descolorido, o amarillo. / Kar huaruna o karhuayak, o karhuayasca, o qquelloyak \&C. El descolorido de rostro de enfermo o flaco" (Gonçález H. 1952 [1608]). 
perfil físico varía de acuerdo al informante, al lugar y al tiempo: a mediados del siglo XX, se lo presentaba con una pequeña lámpara de carburo y con un poncho de lana de vicuña; modernamente, lleva ropa de minero, botas de agua y linterna eléctrica de batería, según el avance tecnológico de la mina. Aunque hay variantes, las botas pueden estar claveteadas $y$, por tanto, ser de cuero; o el duende puede estar descalzo. En Puno, según Van Der Berg, en su Diccionario religioso aimara, lo describen "vestido como si fuera soldado antiguo", pero también vestido de verde musgo, a veces con una finísima capa de vicuña o con el traje impermeable que usan los mineros, y solo en algunas versiones lleva ropa de oro; también en Puno, en otras versiones, se lo describe con ropa antigua recamada de oro y sombrero de plata. En Sandia (Puno) se cree que la cara, sombrero y vestido del muqui son rojizos, semejantes al de un bombero; no usa calzado, pero sí espuelas que producen un ruido enloquecedor, como una pesadilla.

El color rojo del vestido del muqui, que acabamos de mencionar, se relaciona con una acepción de esa palabra en el quechua de Áncash donde muki es 'tierra roja'. Gary Parker y Amancio Chávez en su Diccionario quechua Áncash-Huailas consignan esa entrada como "muki $\mathbf{1}_{1}$.s. Piedras blandas y rojas usadas como tiza". Esa palabra actualmente es base de la expresión híbrida quechua-castellano "muqui niña", que es "muchacha con la cara pintada con tierra roja' (información personal del Dr. Julio Flor Bernuy, natural del distrito de Yanama, provincia de Yungay, dpto. de Áncash). Este es tan solo un ejemplo del abanico de posibilidades de descripción del atuendo del muqui.

Otro significado de la palabra muqui es 'asfixia', acepción que consignan Jorge Lira y Mario Mejía en su diccionario: "múkiy. s. i.v.a. Sofocación, acto y efecto de asfixiar por sofocación. Sofocar, ahogar, asfixiar, quitar la respiración, oprimir y privar del aire" (LiraMejía 2008) o el sustantivo "múki. m. Asfixia, ahogo producido por sofocación o cerrando las vías respiratorias". También Julio Calvo en su diccionario recoge esa acepción como verbo "mukiy. ahogar, asfixiar" y "ahogo, asfixia"; además "muki (mukiy), asfixia; [cult.] [...] // mukikuy, asfixiarse; ahogarse; [anim.], encalmarse; [mat.]" (Calvo 2009). Las acepciones del sustantivo o verbo coinciden en la idea de muerte por ahogamiento. Ese concepto se relaciona con las condensaciones de gases venenosos que se desplazan lentamente por los socavones a unos $50 \mathrm{~cm}$ del suelo, que tienen efectos letales y pueden producir asfixia inmediata.

En la mina, se considera que esos gases en el interior de la mina son los jumpes ('sudores') originados por el aliento fétido del muqui y son visibles; para salvarse, el minero debe tirarse al suelo $y$ hacerse el muerto hasta que pasen. Se los configura como sujetos que tienen ojos, pueden observar y matar. Aunque en otras versiones, los jumpes son los espíritus de los mineros que han muerto en la mina, cuyas almas penan por los socavones al no haberse podido rescatar sus cuerpos. Dentro de ese contexto, encajan los vocablos registrados por Gonçalez Holguín en el siglo XVII en su vocabulario quechua (1952 [1608]), relacionados con padecimiento: los verbos "Muquini, muqquiccuni. Callar, sufrir" y "Muqquicuni. Disimularse, encogerse, no comunicar", y el sustantivo "Muqquicuy. Disimulación". Como vemos, se trata de una acepción de antiguo cuño.

Otro de los significados de las palabras muqui / mukiq en Huancavelica es "el acto de torcer', 'ahorcar' (Salazar Soler 2006), tal vez por el efecto de la sílice ${ }^{13}$ que produce la silicosis, por la inseguridad y los accidentes en la mina. Al ser la mina un universo negado a los seres humanos que lo hollan, se ha relacionado al muqui con la muerte como castigo que inflige a los que ingresan en sus dominios.

Actualmente, la palabra "muqui" es popular en el mundo huanca: es parte del nombre del pueblo Muquillanqui 'sandalia del muqui' (reconocido el 9 de mayo de 1939), en el

${ }_{13}$ La percepción del minero de lo que significa ese polvo se puede encontrar en el huaino "Huraña tierra" "Hoy el triste obrerito / trabaja lleno de martirio /; / agotado mucho en la mina / con ese polvo venenoso." (Bonilla 1974: 31). 
distrito de Marco, provincia de Jauja del departamento de Junin y de la provincia Muquiyauyo (reconocida el 19 de noviembre de 1932), también en ese departamento, cuyo nombre está asociado a una leyenda que se remonta a la época de la expansión incaica en la esa zona y al rapto de la joven más bella del pueblo por el muqui ${ }^{14}$.

Actualmente, dentro del arte, hay anualmente un concurso pasqueño de cuento sobre el muqui con la publicación de los relatos ganadores. El muqui forma parte de la literatura en relatos como El retoño, de Julián Huanay, donde unos niños juegan con el muqui en una mina abandonada; Cholito en los Andes mágicos, de Óscar Colchado, donde unos niños son ayudados por el muqui; en El prefecto, de César Pérez Arauco, el muqui es atrapado por mineros y tiene que trabajar para ellos; en Madre cerreña, de Ricardo Jurado Castro, el muqui cambia la orientación de la mina de alta calidad; Zenón Airan Díaz, en Fantasmandinos, nos dice que los muquis maléficos violan a los trabajadores, entre otras fuentes literarias que tocan el tema. También hay un pasacalle "El muqui" con letra y música de Chalena Vásquez; y se ha presentado la obra de teatro "El Muqui, un duende por el Perú". Hay historietas como "El trato con el muki" de Elías Zenteno.

\section{Descripción física del muqui}

Según las diversas descripciones del muqui, su cuerpo no es armónico: es pequeño, fornido, su cabeza está unida al tronco sin cuello, es de rostro muy blanco y colorado, cubierto de vellos y barba blanquecina, larga, alcaparrosa; tiene cabellos rubios, brillantes y largos; también en la zona de Oruro se lo describe como un enano viejo. Los mineros de Huancavelica dicen que tiene una vista excelente y que sus ojos son rojos y brillan en la oscuridad; su mirada es dura, agresiva, penetrante y con reflejos metálicos. Algunos informantes señalan que tiene dos cuernos en la cabeza con los que destroza las rocas y abre vetas; sus orejas son en punta, según la tradición de Cerro de Pasco. Su voz es grave y ronca. Lleva en la mano un farolito. Su ropa le cubre las piernas, que son como las del cuervo o ganso y camina como pato debido a que sus pies son muy grandes y puede tener la punta hacia atrás; en otras versiones anda saltando como venado. Tiene el miembro viril muy grande y lo puede envolver en la cintura como una correa o dejarlo suelto. Esto hace que los mineros tengan cuidado para no pisarlo; además, por tener el muqui deseo sexual muy intenso, se evita que las mujeres ingresen a la mina porque podría violarlas, según creencia en Sandia (Puno).

El muqui puede metamorfosearse, se transforma en un animal o un hombre blanco y rubio, para engañar a los mineros y presentarse entre ellos. También puede tomar la forma de un perro o sapo, o renacuajo.

\section{Perfil del muqui}

El muqui es un duende ambiguo. Puede premiar o castigar. Los mineros pueden ser guiados por él para encontrar oro, plata y cobre, con la condición de cederle la mitad de la riqueza que se encuentre. Él sabe si el minero que promete es honesto, pero generalmente los pactos con el muqui terminan con la muerte del minero. Se ha destacado en las fuentes aimaras su caracterización negativa, más que la positiva: "Ser maligno" (Van der Berg 1985), "Espíritu maligno" (Deza 1989).

El duende de las minas es muy bromista: lanza piedrecitas en la cabeza a los mineros que descansan en su jornada laboral, hace ruidos en las minas, roba las herramientas y las esconde, sin que se pueda dar una razón lógica. Lanza potentes silbidos para alertar sobre el peligro y salva a los mineros de su simpatía. Es comunicativo, gusta jugar con los niños y se puede comunicar en los sueños.

\footnotetext{
14 El topónimo Muquiyauyo puede tener alguna relación con la minería. Según tradiciones, los incas pusieron mitimaes de Yauyos, quienes se dedicaron a la extracción de tierras de colores en Jalamachay ('cueva del maíz'), donde excavaron galerías y túneles y se encontraron con el muqui. Entonces Muquiyauyo significaría 'yauyos muqui' o 'yauyos mineros', por la relación de la palabra muqui con la minería.
} 
El muqui se abstrae en el trabajo o en el juego $y$, en ese caso, puede ser observado sin que lo advierta; y este es el momento en que un minero podría intentar atraparlo inmovilizándolo con el shicullo (lazo de cerda de caballo). De ser así, se verá obligado a trabajar para el minero o deberá entregar una gran cantidad de oro debido a que por la luz se desvanece si lo sacan de la mina.

Como el muqui es el dueño de la mina, tiene poder para paralizarla y cambiar el sentido de una veta, sin una razón aparente. Es vengativo si no se le deja ofrendas: puede empujar a la persona de una tolva, apretarle el cuello, tirarle un pedrón en la cabeza o amarrarle los pies para que no pueda huir de la explosión de dinamita. Como castigo, puede entorpecer y dificultar la extracción del mineral o aliviar el trabajo, de acuerdo a la simpatía que le genere algún minero, Solo excepcionalmente presta ayuda. Y, si se avecina un peligro, previene a los mineros que le inspiran confianza para que tomen las medidas adecuadas.

El muqui puede enajenar la razón de las personas que se encuentran con él por la noche. Puede causar enfermedades mortales como el muquihuayra's ('viento del muqui'), que produce granulaciones que crecen, impiden laborar y dejan paralizado al trabajador. Esa enfermedad ataca a quienes no han cumplido una promesa hecha al muqui o han entrado en la mina sin pedirle permiso. Se cura por mediación del pongo del muqui, quien se comunica con él, le pregunta para cerciorarse si es el causante del mal, como ya se mencionó. Además, le ofrece coca, trago y cigarro, y una mezcla de alcohol y polvos minerales (huinzo, polvo azul; y caruamuqui, polvo amarillo).

El muqui también puede producir la kutincha, enfermedad que castiga el incumplimiento de un pacto o transgresiones de los espacios sagrados. El enfermo de kutincha empieza con síntomas de mucho sueño, vértigo, $\mathrm{y}$, al cabo de algunos días, entra en un estado de sonambulismo generador de un debilitamiento progresivo que puede ser mortal. Otro síntoma de esta enfermedad es que la persona comienza a "secarse" comenzando por los miembros superiores y luego ataca todo el cuerpo ${ }^{16}$. El muqui puede curar este mal a través de la mediación de un especialista, solamente unavez que el enfermo ha cumplido con las promesas hechas en el pacto. También se puede aplicar al enfermo el uywachay, que es "Realizar una cura mágica con un animal pequeño" (CerrónPalomino 1976), lo que usualmente llamamos "pasar el cuy" por el cuerpo del enfermo para luego abrir el animal con el fin de leer en las vísceras el diagnóstico. Ese rito también se realizaba durante el incanato, como se lee en las crónicas de extirpación de idolatrías de Cajatambo.

\section{Las ofrendas}

El culto a los dioses de la mina se registra desde el incanato, pero debió iniciarse antes. En las crónicas no se menciona el nombre muqui. Antonio de la Calancha refiere:

Usavan los Indios que van a las minas de plata, de oro o de açogue, adorar los cerros o minas, pidiéndoles metal rico, $i$ para esto velan de noche, beviendo i baylando, sacrificios que azen a la riqueza; a los de oro llaman Coya, i al dios de las minas de plata i a sus metales Mama, i a las piedras de los metales Corpa, adóranlas besando, i lo mismo al soroche, al açogue $i$ al bermellón de açogue, que llaman Ichma, o Linpi, $i$ es muy apreciado para diversas supersticiones. (Calancha 1976 [1638], t. II: 842).

Como el muqui protege y vigila celosamente el mundo subterráneo, la explotación minera

15 El muquihuayra es una enfermedad producida por la absorción de emanaciones de la mina.

16 Los mineros relacionan la kutincha con la silicosis y con los cambios de temperatura durante la faena en la mina y al salir. Para curarla, el curandero frota el cuerpo de la persona con un sapo verde, le da una toma de toronjil, manzanilla, urqu wira-wira y retama y le frota el cuerpo con estas yerbas invocando al muqui pidiendo que devuelva "el sonqo al enfermo", es decir, le devuelva la vitalidad que le ha quitado porque está sonqueado (Salazar-Soler 2006: 168-169). También una persona puede ser sonqueada por olvidarse de ofrecer las ofrendas al muqui o por haber ocultado mineral a sus compañeros, venderlo y beneficiarse solo. 
debe iniciarse con el ritual del pago o pagacu (ofrenda) para tener su autorización y de la Pachamama, wamani o jirca, apelativos quechuas con los que se menciona a la tierra (cerros y minas). Solo voy a referirme a la mesa principal y no a la mesa pequeña.

Las ofrendas son de dos tipos: objetos (chicha, aguardiente, coca, cigarros, velas), animales (llamas seleccionadas o carneros, a veces vacas) y el kuche, que es la ceremonia para obtener riqueza en la que se entrega como ofrenda una persona (una chica muy joven o un hombre). Las ceremonias siguen un rito tradicional, pueden ser personales, incluso un pacto con el muqui; o grupales, que pueden contar con el apoyo de dinero o insumos de la patronal minera.

La ofrenda personal en Cerro de Pasco y Vichos consiste en asperjar con chicha o aguardiente la tierra y el aire y colocar las dádivas (aguardiente o chicha, coca, cigarros $y$ en algunas versiones velas y claveles rojos ${ }^{17}$ ) en la boca de las minas, o entradas principales, para que el muqui las recoja. También se deja las ofrendas dentro de las minas en las paredes y en el ojo del muqui, que es el lugar donde hace sus apariciones, o en las apachetas (promontorios de piedras en determinados lugares de la mina donde se deja hojas de coca $)^{18}$. En Castrovirreyna, los mineros hacen regalos al muqui que representan los tres reinos de la naturaleza: un puñado de coca, una botellita de pisco o aguardiente, un terrón de champa, naranjas maduras, huesecillos de zorro, vicuña o cóndor, una moneda de plata y flores del campo, según testimonio recogido por Alfonsina Barrionuevo. En Puno se deja vino, coca y cigarro impregnados en lugares donde se chaccha la coca. En Huancavelica, existe la creencia de que el muqui ingiere heces $y$ las convierte en oro, por lo cual algunos mineros defecan en el lugar de trabajo.

La época de la ofrenda grupal en Huancavelica por los años 80 era febrero y agosto; actualmente se realiza solo una vez al año en la primera semana de agosto, en especial martes o viernes. En Oyón se presentan las ofrendas en febrero, en cambio, en Puno puede ser cualquier día en el mes de agosto, que es la época en la que la Pachamama se abre para recibir las ofrendas con las que recupera su vigor. En Huancavelica realiza la mesa principal el yachaq ('el que sabe'), también llamado pongo (sirviente) ${ }^{19}$, tal vez por una supeditación absoluta a la voluntad del muqui; y en Puno, está a cargo del tío. Ellos son especialistas en ofrecer la mesa grande para el muqui y la mesa pequeña para la Mamapacha.

Antes, en Huancavelica, la mesa principal se tendía en la confluencia exacta entre el número de wamanis (cerros que rodeaban la mina) y las esquinas del lugar del ritual; actualmente, como hay cambio de minas, se ha omitido ese requisito. Se busca el "ojo de muqui" y el pongo entierra el feto de llama o cualquier animal menor en el lugar de la mina donde se ha producido el accidente más reciente. Para el ritual, se tiende un mantel blanco de $50 \mathrm{~cm}$, sobre el cual se coloca a la derecha una rama de ichu, a la izquierda una de retama y otra de molle. Debajo, a la derecha, maíz negro macho o una espiga de trigo; al lado izquierdo, maíz blanco y gris (si no había otros colores, pero nunca negro). En el tercer plano, se coloca una botella de licor comprado en el pueblo (no cañazo); a la izquierda, dos botellas pequeñas de cañazo y de "verdeojo" (licor del lugar en base de hierbas maceradas en cañazo);

17 Según Rosalind Gow y Bernabé Condori, la ofrenda de claveles se ofrece por ser "flores sagradas de los apus", que actúan como refuerzo adicional (Gow y Condori 1976: 7).

18 Las apachetas están relacionadas con el culto a la Tierra. Bernabé Cobo menciona que esa palabra se usaba para referirse a los cerros y a los promontorios de piedras: "las peñas o piedras grandes, los riscos y quebradas hondas, los altos y cumbres de los cerros y collados, que llaman apachitas: adoraban estos lugares, diciendo que cuando acababan de subir la cuesta arriba y llegaban a lo alto, descansaban allí de la subida. Tenían hechos grandes montones de piedras, así en las dichas apachitas como en las llanadas y encrucijadas de caminos, a los cuales también hacían reverencia y ofrendaban" (Cobo 1964 Ś1653S: 166).

19 Se aclara la idea del pongo con la explicación de José María Arguedas. "El pongo es el servidor, ya del auki, ya de los wamanis". Y más adelante: "El pongo es el sirviente de los wamanis, iniciado en el oficio de evocar y ponerse en comunicación con los espíritus de las montañas Ś...Ṣ” (Valcárcel 1984: 284-285). Así se establece su conexión con el pongo del muqui. 
también se puede colocar a la derecha una con ajo macho macerado y otra con ajo hembra macerado. En el siguiente nivel, se ponía adornos de metal brillante e illas (amuletos) de llama; a la izquierda, adornos de flores plateadas y doradas, y semillas en par hembra y macho.

Encabezando la mesa, a la izquierda se coloca una estatuilla bifronte: por un lado, representa a la Virgen del Rosario; y por el otro, una mujer cubierta con una manta de colores portando trigo en los brazos y a la derecha la estatuilla del muqui. Frente a cada uno de ellos se coloca la mitad de mates (que corresponde al número de cerros que rodean la mina) que contienen el mismo tipo de maíz molido de la mesa que al final se entierran en cada cerro.

El pongo empezaba invocando seis veces los nombres: muqui, anchanchu, muqui supay, supay, arrierito. La primera vez levantando la estatuilla del muqui; la segunda, la rama de ichu de la derecha, hasta llegar al sexto plano. Ruega al muqui que permita entrar a la mina, ayude a encontrar mineral, encontrar la veta y permita riqueza y bienestar. Luego, invoca a la Virgen del Rosario y a la Pachamama, levantando los objetos de la izquierda, pide fertilidad para la mina, protección para los mineros, resguardo contra el amaru; también invoca a Juana Tintaya. Al terminar, el pongo va a los rincones de la mina asperjando licor y masa de granos molidos con licor $^{20}$. Y si hubo accidentes, se entierra un poco de cada ofrenda en el lugar de los hechos. Luego, uno de los mates se entierra en el lugar de la mesa principal (antes se enterraba un feto de llama). Al terminar, como se mencionó, se entierran los mates en cada uno de los cerros y se echa un chorro de sangre de llama o cordero (Salazar-Soler 2006). Alfonsina Barrionuevo relata haber escuchado a Jiménez Borja que de niño vio en la mina Choquellimpi, costa sur, matar y untar con sangre de un toro las paredes de la mina para que esta la bebiera y después arrojar el corazón palpitante para que lo comiera durante unos festejos de carnaval.
También en la mina de Uchucchahua ('anciana pequeña') en Oyón (al norte de Lima), existe la creencia en el muqui, pero, según Rodríquez (2004), los ritos se dirigen no al muqui sino a la Pachamama. Al encontrar una veta con mineral de ley, los obreros e ingenieros mineros llenos de alegría challan ${ }^{21}$ - hacen aspersión ritual_, es decir, "bautizan" la veta con chicha, aguardiente, cerveza, chicha, vino y coca. Se festeja a veces con una misa realizada en el mismo lugar de la veta; además con bailes, ofrendas de flores en agradecimiento a la Pachamama por ser una madre generosa que otorga a sus hijos el mineral y le piden que no haya accidentes. Luego hay baile general con una banda musical hasta el amanecer (Rodríguez).

Otro ritual en Oyón -que fue llevado de las minas de Orcopamapa, en Arequipa, a las de Uchucchacua- es el ya mencionado huilancho. Se realiza a inicios de año, generalmente en febrero. El huilancho es el pago más importante a la Pachamama que se hace con el fin de aplacar su ira y poder seguir explotando la mina con cierta seguridad de que no haya accidentes fatales y se encuentre abundante mineral. El responsable del rito es llamado "sacerdote", quien entrega a la Tierra la sangre de una hermosa llama blanca virgen, a la cual "atada de las cuatro patas y con un filudo cuchillo, le sacan el corazón palpitante. Si late más de un minuto fuera del pecho del animal, esto significa que habrá bastante mineral y pocos accidentes" (Rodríguez 2004: $30)$. Además, se rocía con sangre de cría de llama blanca las paredes de una nueva construcción del interior de la mina. Los mineros participan con respeto religioso y con alegría bebiendo chicha, licor y chacchando coca; se visten con elegancia, se envuelven el cuello con serpentina multicolor y se ponen talco en la cara. (Rodríguez 2004).

Una tercera ceremonia en Oyón es la mesada, un pago a la tierra para aplacar a los cerros, donde moran los auquis, que son espíritus protectores de la población. Tienen sed

20 Durante el incanato también se presentaba a los dioses el sanco, ofrenda de maíz molido mezclado con sangre.

${ }^{21}$ Palabra de origen aimara, viene del verbo ch'allaña 'asperjar', 'asperjar ritualmente' (en ceremonias propiciatorias, inauguraciones, etc.). 
de sangre humana y por eso se producen accidentes personales en el socavón. Para evitarlo, se les ofrece la mesada: se coloca una mesa mediana, se extiende un mantel blanco y encima se pone todo tipo de licor, sobre todo aguardiente, coca, frutas, carne de animales tiernos ("guagüitas") y numerosas flores frescas.

La gente se adorna con serpentinas al cuello y se pintan la cara con perfumados talcos de colores. Toman licor, chacchan $y$ elevan sus plegarias con mucha devoción a los Auquis del lugar.

Al final, todo lo que se ofrece al cerro: coca, licor, chicha, cigarro y flores se entierran en un hoyo que hacen en el socavón de la mina en señal de paga a los temidos y sedientos Auquis intentando aplacar su implacable furia. (Delgado 2004: 30-31)

En Puno se realiza otro tipo de ceremonia. El ingeniero puneño Víctor Paredes Argandoña ${ }^{22}$ manifiesta que la creencia en el chinchilico (nombre que dan al muqui) está muy arraigada en ese departamento, sobre todo en la zona oriental. Señala que antes de empezar a trabajar una mina se debe realizar el pago que, además, es anual. Para el efecto, se compra la mesada ya lista en Juliaca por un precio de que fluctúa entre 100 y 200 soles, dependiendo de su calidad. Contiene feto de llama, coca, dulces, confites (caramelos), vino, objetos de cobre y hierro (como medallitas pequeñas). En algunas ceremonias, se sacrifica una llama cuya sangre se echa en la tierra; las ofrendas de animales se realizan más esporádicamente.

La mesada la realiza alguien experimentado, el tío, que es una persona de mucha edad y que siempre se ha dedicado a esa actividad. Para realizar el pago se sube a un cerro a unos 4000 o 4500 msnm. A las 10 p.m. se abre la mesada y empieza el ritual. Todos los participantes se sientan alrededor y el tío llama al dueño de la mina, se aproxima a una base de cerámica con incienso y da un soplo. El tío bendice para que haya abundancia. Enseguida, llama al dueño de la mina, del puñado de coca que hay saca tres hojas de coca, para cumplimiento de sus deseos (riqueza, salud, familia...) y las introduce en un vaso con un poco de vino; se persigna y las pone en un vaso vacío. Luego cada uno de los asistentes realiza el mismo ritual. Al terminar, el tío lleva toda la ofrenda más arriba de la montaña, donde está lista la bosta (excremento seco de vaca) que le sirve para una fogata que enciende con alcohol. Quema todo y mira; luego el tío dice que todo va a ir bien. Después los participantes pueden irse, brindar o quedarse.

Los ritos con sangre son universales, ya que la tierra ofrece sus frutos y el sacarlos es quebrar el proceso de gestación. Según Mircea Eliade:

la idea de que la creación se efectúa mediante una inmolación o una autoinmolación. [...] La promoción del sacrificio sangriento en cuanto condición de toda creación - tanto cosmogónica como antropológica- refuerza, por una parte, las homologaciones entre el hombre y el cosmos (porque también el universo deriva de un gigante primordial, un macroantropos); pero, sobre todo, introduce la idea de que la vida solo puede engendrarse partiendo de otra vida que se inmola. Este tipo de cosmogonías y antropogonías tendrán sus consecuencias considerables: se llegará a no poder llegar a concebir "creación" no "fabricación" posibles sin previo sacrificio. Así podemos referirnos, por ejemplo, a los ritos de la construcción, por medio de los cuales se transfiere la vida o el "alma" de la víctima al propio edificio; este se convierte, de hecho, en el nuevo cuerpo, del cuerpo arquitectónico, de la víctima sacrificada. (Eliade 1959: 29-30)

Si no se realiza el ritual y se empieza a trabajar una mina sin autorización del muqui o la Pachamama, estos seres sienten mucha hambre, es decir, rabian. Igualmente, si la

${ }^{22}$ El ingeniero Víctor Paredes Argandoña trabaja en el sector minero en Puno desde hace 22 años. 
magnitud de la ofrenda es insuficiente, tienen hambre. Ese sentido de apetito biológico de la palabra "hambre" mantuvo su significación incaica en la Colonia ${ }^{23}$. Cristóbal de Molina en Ritos y fábulas de los incas (1573), dice que por la extirpación de idolatrías los indígenas habían dejado de presentar ofrendas a las huacas y que ellas por falta de sustento estaban "hambrientas", por lo cual los sacerdotes indios predicaban la urgencia de rendirles cultos tradicionales:

Salieron muchos predicadores luego de los indios, que predicaban así en las punas como en las poblaciones, andaban predicando esta resurrección de las huacas andaban por el aire secas y muertas de hambre porque los indios no le sacrificaban ya, ni derramaban chicha y que habían plantado muchas chacras de gusanos para plantarlos en los corazones de los españoles y ganados de Castilla y los caballos y también en los corazones de los indios que permanecen en el cristianismo y que estaban enojadas (Molina, 1573 [1947]: 29)

Es así como en algunas creencias y ritos actuales pervive un panteísmo que se entronca con algunas concepciones y tradiciones del pasado incaico. Aunque han cambiado las cosmogonías, la visión de la realidad y las relaciones de producción, el trabajador minero nativo siente reverencia por las deidades del socavón; y el pago es una vuelta al orden, una manera de armonizar la vida del hombre con la naturaleza violentada. Más aún, dentro del concepto de sacralidad del uku pacha y de la hierofanía de la Pachamama, para el minero la relación con el muqui y su intermediación para extraer mineral cobra una trascendencia decisiva. De ahí dimana su reverencia y acatamiento total a las tradiciones ancestrales de su culto como "el dios del socavón", puesto que rige las coordenadas de la existencia de los minerales, como la voluntad omnímoda a cuyo arbitrio se supedita la riqueza minera del mundo subterráneo.

23 Guaman Poma de Ayala dice que hay hechiceros que se refugian en las cuevas para dormir y les rinden culto para que no los coma: "Otros hechizeros entrando a dormir a las cueva y adoran a las dichas cuevas y dize machay mama ama micuuanquicho allilla punochiuay. Cueva no me comays hasme dormir bien y guardame esta noche diciendo esto le dan de comer mays mascado o coca y le enplasta al dicho cueva y hasta este tiempo lo uzan los indios" (1989 [1615?]: 276). En otro pasaje Guaman Poma de Ayala también se refiere a los hechiceros como propaladores de la religión dando una imagen de que las huacas tenían vida, necesidades fisiológicas (hambre y sed) y se comunicaban verbalmente: "estos engañavan a los hombres diziendo que come y veven y hablan las uacas" (Guaman Poma, 1989 [1615?]: 280). 


\section{REFERENCIAS}

APRODE PERU Estudio socioeconómico- Comunidad de Muquiyauyo. Dirección Ejecutiva de Programas y Proyectos de Desarrollo-ONG'D. Registrado el 25 de mayo de 2014 de http:// es.scribd.com/doc/133415386/Estudio-Socioeconomico-Comunidad-de-Muquiyauyo

Arriaga De, Pablo Joseph (1920 [1621]) La extirpación de idolatría en el Perú. Lima, Imprenta y Librera Sanmarti y Cia.

Barrionuevo, Alfonsina (1974) El muki y otros personajes fabulosos. Lima, s. e.

Bertonio, Lvdovico (1984 [1608]) Vocabulario de la lengva aymara. La Paz. Ceres, y Fez Musef. Edición facsimilar.

Bonilla, Heraclio (1974) El minero de los Andes: Una aproximación a su estudio. Lima, Instituto de Estudios Peruanos.

Calvo, Julio (2009) Diccionario Quechua-Español Español-Quechua. Lima, Universidad Ricardo Palma.

Cerrón-Palomino, Rodolfo (1976) Diccionario quechua: Junín-Huanca. Lima, Ministerio de Educación e Instituto de Estudios Peruanos.

Cobo, Bernabé (1964 [1580-1617]) Historia del Nuevo Mundo. Madrid, Colección Rivadeneira, t. II.

Deza Galindo, Juan Francisco (1989) Diccionario aymara-castellano castellano-aymara. Lima: CONCYTEC.

Duviols, Pierre (1986) Cultura andina y represión. Procesos y visitas de idolatrías y hechicerías Cajatambo, siglo XVI. Cuzco, Talleres Gráficos del Centro Bartolomé de las Casas.

Eliade, Mircea (1959) Herreros y alquimistas. Madrid, Taurus.

Fernández Juarez, Gerardo (2006) "Kharisiris de agosto en el altiplano aymara de Bolivia". Volumen 38, N 1, 2006. Páginas 51-62, Chungara, Revista de Antropología Chilena http://www. google.com.pe/url?sa $=\mathrm{t} \& \mathrm{rct}=\mathrm{j} \& \mathrm{q}=\& e s \mathrm{rc}=\mathrm{s} \&$ source $=$ web\& $\mathrm{cd}=3 \& \mathrm{ved}=0 \mathrm{CCYQFjAC \& url}=\mathrm{http}$ \%3A\%2F\%2Fwww.scielo.cl\%2Fscielo.php\%3Fpid\%3DS0717-73562006000100006\%26script\% 3Dsci_arttext\&ei $=3 A-h U-L B D I u y y A S 06 Y L w B w \& u s g=A F Q j C N E R w c U A u P f G X F J h p P D v E U F N$ wL5iew\&bvm = bv.69137298,d.aWw Registrado el 23 junio 2012.

Gentile Lafaille, Margarita E. (1999) Huacca Muchay-Religión Indígena. Religión, creencias, juegos área andina argentina prehispánica-colonial-actual. Buenos Aires, Instituto Nacional Superior del Profesorado de Folklore.

Gonçales Holguín, Diego (1952 [1608]) Vocabulario de la lengua general de todo el Peru llamada lengua qquichua o del inca. Lima: Edición del Instituto de Historia, Imprenta Santa María.

Gow, Rosalind y Condori, Bernabé (1976) Kay Pacha. Tradiciones Cuzqueñas. Tradición oral andina. Cuzco, Centro de Estudios Rurales Andinos "Bartolomé de las Casas".

Guaman Poma De Ayala, Felipe (1989 [1615]) La nueva corónica y buen gobierno. París, Institut D'Ethnologie. 
Layme Pairumani, Félix (2004) Diccionario Bilingüe Aymara-Castellano. La Paz, Consejo Educativo Aymara (CEA), tercera edición.

Lira, Jorge A. y Mejía Huamán, Mario (2008) Diccionario quechua-castellano castellano-quechua. La Paz, Universidad Ricardo Palma. Versión modernizada del Diccionario quechua de Jorge Lira. Publicado en 1944.

Molina, Cristóbal de (1573 [1947]) Ritos y fábulas de los incas. Buenos Aires, Editorial Futuro. http://es.scribd.com/doc/50568715/MOLINA-Cristobal-de-del-Cuzco-1573-1947-Ritos-y-fabulasde-los-incas Registro 20 junio 2014.

Parker, Gary J. y Chavez, Amancio (1976) Diccionario quechua Ancash, Huaylas. Lima, Ministerio de Educación e Instituto de Estudios Peruanos.

Rodríguez Saucedo, María Betzabé (2004) Léxico de la minería. Estudio semántico-lexicográfico de la unidad minera de Uchucchacua. Lima, Universidad Nacional Mayor de San Marcos. Tesis para optar el título profesional de Licenciada en Lingüística.

Salazar-Soler, Carmen (1997) "La divinidad de las tinieblas". En: Bulletin de l'Institut Français d'Études Andines, Nºspécial: "Tradición oral y mitología andinas". Lima, Tomo 26, №3 http:// www.comunidadandina.org/bda/docs/IF-CA-0001.pdf Registro 5 mayo 2014.

Salazar-Soler, Carmen (2006) Supay Muqui, dios del socavón. Vida y mentalidad minera. Lima, Fondo Editorial del Congreso.

Samamé Boggio, Mario (1979) El Perú Minero. Historia. t. I, Lima, INCITEMI.

Santo Tomás, Domingo de (1560) Vocabulario general de la lengua de los indios, llamada quichua. Valladolid, Francisco Fernández de Cordoua. https://archive.org/stream/ lexiconovocabula00domi\#page/n3/mode/2up Reg. 1 julio 2014.

Valcárcel, Luís E. (1984) Historia del Perú antiguo a través de la fuente escrita. Barcelona, Editorial Mejía Baca.

Van Den Berg, Hans. O.S.A. (1985) Diccionario religioso aymara. Iquitos, Centro de Estudios Teológicos de la Amazonía (CETA). Instituto de Estudios Aymaras (IDEA).

Fecha de recepción: 15-08-16

Fecha de aceptación: 21-12-16 
